\title{
Variation of Microstructural and Mechanical Properties With Respect to Polarity in Shielded Metal Arc Welding of Mild Steel
}

\author{
Bijaya Kumar Khamari ${ }^{a^{*}}$, Balamurali Gunji ${ }^{b}$ \\ Department of Industrial Design \\ National Institute of Technology, Rourkela, Pin code - 769008, India \\ E-mails: abijayaa.khamari@gmail.com, bbmgunji@gmail.com \\ ${ }^{*}$ Corresponding author \\ Swapan Kumar Karak \\ Department of Metallurgical and Materials Engineering \\ National Institute of Technology, Pin code- 769008 Rourkela, India \\ E-mails: skkarak@gmail.com \\ Bibhuti Bhusan Biswal \\ Department of Mechanical Engineering \\ National Institute of Technology, Meghalaya, Pincode-793003, India \\ E-mails: bibhuti.biswal@gmail.com
}

(Received November 16, 2018; Accepted February 7, 2019)

\begin{abstract}
Welding has been done by taking mild steel as work piece material in shielded metal arc welding (SMAW) process. Material thickness and current were considered as input parameters. Joining of metals has been completed in two ways. In first process double pass welding has been done in which 1st pass was in reverse polarity and the second pass was in straight polarity and in the 2 nd process both the passes of welding were completed with straight polarity. The comparison of microstructure and impact toughness has been investigated. It was found that more amount of heat was generated in the 2 nd process as compared to the 1st process. Therefore, growths of grains in heat affected zone occurred and maximum growth occurred in 2nd than 1st process. Impact strength increased with decrease in current value and increase in material thickness respectively. The impact strength values for 1 st process welding were relatively less as compared to 2 nd process.
\end{abstract}

Keywords- Shielded metal arc welding, Microstructure, Impact energy, Polarity, Fusion zone.

\section{Introduction}

Now a day the all researchers are focusing their work on microstructure and mechanical properties of the welded structure to improve the weld quality. Therefore, many new methods have been hosted. According researchers welding process should be cost effective with optimized parametric combination to get better quality of the weld. Shielded metal arc welding is the most common type of welding with less cost and more productivity. To know the weld quality the most important thing is to investigate the microstructure and different mechanical properties like micro hardness, impact toughness and weld strength of welded specimen in different zones such as fusion zone, HAZ and less heat affected zone. In microstructure mostly acicular ferrite and pearlite grains have been seen. The main objective is to increase the weld strength, impact toughness with better microstructure and more durable welded joints. Shield metal arc welding techniques were used to find out the influence of the amount of heat, which was supplied to measure the mechanical properties of low carbon steels. Hardness, impact energy and tensile strength of the welding portion have been 
International Journal of Mathematical, Engineering and Management Sciences

Vol. 4, No. 2, 521-530, 2019

https://dx.doi.org/10.33889/IJMEMS.2019.4.2-042

calculated (Bodude and Momohjimoh, 2015). Many authors tried to find out the influence of process parameters on the yield strength in the medium carbon steel graded AISI 1040. They investigated the yield strength and microstructure of the MIG welded sample welded at different welding parameters (Hooda et al., 2012).

The investigation of mechanical properties and microstructures of the welded joints by optical Microscopy, SEM, micro hardness test and the tensile test has been done in this work. The authors found out that the weld zone had an as-cast structure with equiaxed shaped grains. The columnar grains form on one side of the welding seam as well as equiaxed crystal on the other side. The micro hardness decreased in the order Base Metal > HAZ > Welding zone (Wansheng et al., 2008). The effect of various process parameters on welding of IS 2062 mild steel plate using GMAW with a copper coated mild steel wire of $0.8 \mathrm{~mm}$ diameter have been found out. The various results like bead width, bead height and depth of penetration were calculated by using Response surface methodology. The conclusion was found that the error between experimental and theoretical values was less than 2\% (Srivastava and Garg, 2017). IS2062 mild steel and EN8 has been taken as workpiece materials for dissimilar metal joining in metal inert gas welding. The authors analysed different mechanical properties and microstructure of welded specimen with low and high heat inputs as well as with and without post weld heat treatment (Chennaiah et al., 2016). In this work, the authors have been chosen IS 2062 E250 grade steel as work specimen for investigation of different responses like yield strength and tensile strength by taking the welding current, feed rate, number of welding passes as input parameters. Response surface methodology used to find out optimal combination input process parameters to get optimized results (Jagtap et al., 2017). The examination of the effect of different process parameters like electrode size, voltage, current, shielding gas and arc travel Speed on the hardness of fusion zone have been investigated by using metal inert gas welding and submerged arc welding. The results showed that the value of hardness in MIG welding was lower as compared to SAW (Lala et al., 2018).

There are many advantages and applications of additive manufacturing. With the help of AM process complex material parts can be welded with reduction of material weight and amount of material (Wang and Alexander, 2016). The qualitative comparative analysis has been done between multi value variant, crisp-set and fuzzy-set. Karnaugh maps were very useful to solve multi value minimization problems (Muhammad and Rushdi, 2018). The waste egg shell micro grains both with carbon and without carbon converted to the matrix of Al-Si alloy. The different mechanical properties like hardness, impact strength, toughness as well as compressive strength and microstructure has been observed (Gunwant et al., 2017). Flat plates were considered to find out the stress concentration with the help of the finite element method. The geometry of the flat plates and types of loading were the most important controllable parameters to identify the stress concentration (Gunwant, 2019). The comparison between different criteria of efficiency standards and patents has been done to know which was more effective (Aronov and Zazhigalkin, 2017). Anew method like non homogeneous Gamma process was established through parametric bootstrap methods to find out the confidence interval of the model parameters (Saito and Dohi, 2018). With the help of the combinatorial approach the different start-up demonstration test has been conducted to make a comparative study (Gera, 2018). The comparison between two different processes has been done in this work.

\section{Material and Methodology}

Mild Steel samples were procured and three different sample dimensions were taken, namely $(10 \times 5 \times 0.5) \mathrm{cm} 3,(10 \times 5 \times 0.6) \mathrm{cm} 3$ and $(10 \times 5 \times 0.8) \mathrm{cm} 3$. For each dimension, 6 samples were 
International Journal of Mathematical, Engineering and Management Sciences

Vol. 4, No. 2, 521-530, 2019

https://dx.doi.org/10.33889/IJMEMS.2019.4.2-042

procured. The grade of mild steel used was IS 2062 with the composition tabulated in Table 1.

Table 1. Composition of Mild steel samples used

\begin{tabular}{llccccl}
\hline Element & Carbon & Manganese & Silicon & Sulphur & Phosphorus & Iron \\
\hline Percentage & $0.16-0.18$ & $0.7-0.9$ & 0.4 & 0.04 & 0.04 & Balance \\
\hline
\end{tabular}

Mild steel samples were polished at the edges so as to make it ready for welding. Pedestal grinder in our workshop was used for polishing the edges. In all, there were 18 samples. All the 18 samples were grinded using pedestal grinder in order to make a $\mathrm{V}$-shaped groove. Double pass welding has been carried out. In the first process both the passes have been done with straight polarity. After completion of the first pass chipping operation was done then second pass welding was conducted. In SMAW process after completion of $1^{\text {st }}$ pass welding the impurities of the weld pool mixed with the flux of the filler rod and formed a layer of slag over the weld bead. Therefore chipping operation was necessary to remove the slag for the continuation of $2^{\text {nd }}$ pass welding. But in the second process of welding first pass was executed with reverse polarity and second pass with straight polarity. The total amount of heat that passed to the work piece was more in case of double pass straight polarity than welding with variation of polarity because in reverse polarity welding more heat was transferred to electrode than the work piece. The filler rod was used in this process is mild steel 6013. The chemical composition has been given in Table 2.

Table 2. Composition of the filler metal used during MIG welding

\begin{tabular}{ccccccc}
\hline Element & Carbon & Manganese & Silicon & Sulphur & Phosphorus & Iron \\
\hline Percentage & 0.075 & 0.44 & 0.22 & 0.02 & 0.02 & Balance \\
\hline
\end{tabular}

\subsection{Optical Microscopy}

The samples were grinded using belt grinder. After completion of grinding, the samples were polished using emery papers viz. 1/0, 2/0,3/0 and 4/0 in a progressive manner. Now the samples were cloth polished using Alumina paste and finally diamond polished to get a fine mirror appearance on the surface which needs to be observed under microscope. After polishing, the etchant was prepared which contains $4 \%$ nitric acid and $96 \%$ ethanol. $4 \%$ Nital was used as an etchant for mild steel samples. Preparation of 4\% Nital involved measuring of $96 \mathrm{~mL}$ using measuring flask in which $4 \mathrm{~mL}$ of concentrated nitric acid was added. The polished samples were taken and dipped in the etchant for a few seconds which was kept in a petridish. After etching the samples were taken for microstructural observation under an optical microscope. The different zones of microstructure which have been investigated are given in Figure 1. 


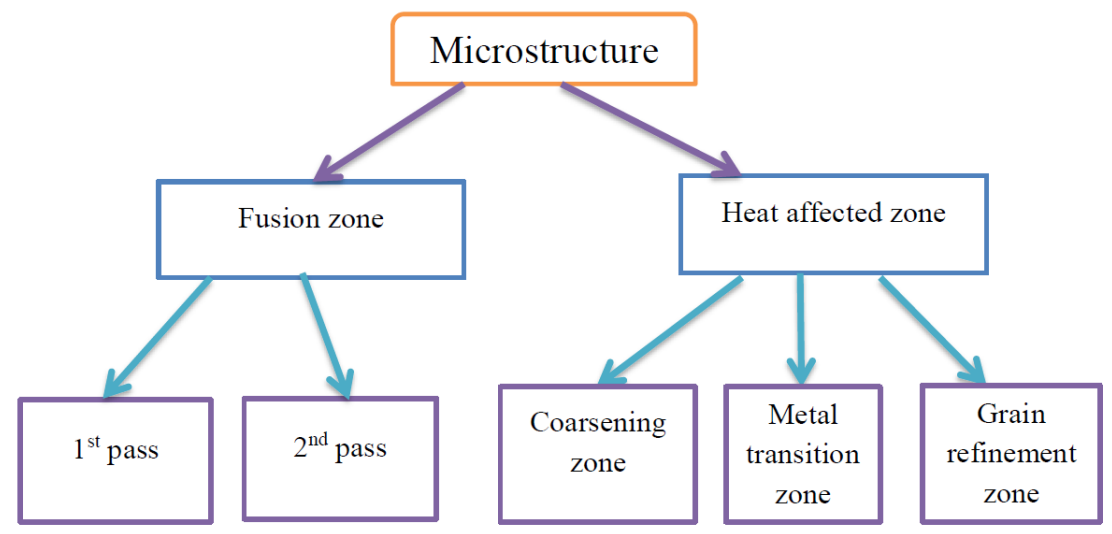

Figure 1. Representation of different zones of microstructure in welded samples

\subsection{Impact Energy}

Charpy V-notch impact test was carried out on the welded specimens with dimensions of the specimens being $10 \mathrm{~cm}$ in length and $1 \mathrm{~cm}$ in width and the thickness varying as in $5 \mathrm{~mm}, 6 \mathrm{~mm}$ and $8 \mathrm{~mm}$. Notched bar impact test of metals provide information on failure mode under high velocity loading conditions leading to sudden fracture where a sharp stress raiser (notch) is present. Although two standardized tests, the Charpy and Izod, were designed and used extensively to measure the impact energy, Charpy V-notched impact tests are more common in practice. The load was applied as an impact blow from a weighed pendulum hammer that was released from a position at a fixed height $h$. The specimen was positioned at the base and with the release of the pendulum, which had a knife edge, stroke and fractured the specimen at the notch. The pendulum continued its swing, rising to a maximum height $\mathrm{h} 1$ which was obviously lower than h naturally. The energy absorbed at fracture was obtained from the difference in potential energy of the pendulum before and after the test. The v-nose which was prepared is given in Figure 2.

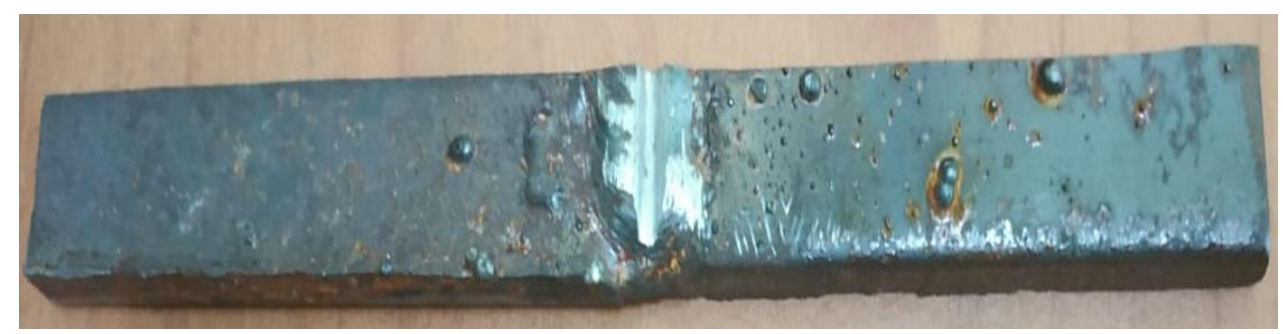

Figure 2. V-nose on the welded mild steel plate for impact test

\section{Results and Discussion}

\subsection{Microstructure Analysis}

Optical microstructures of mainly two zones have been conducted. One is fusion zone and second is heat affected zone in $5 \mathrm{~mm}$ thickness workpiece thickness by the application of $120 \mathrm{~A}$ current. The microstructures during $1^{\text {st }}$ pass welding in both the cases have been given in Figure 3. 


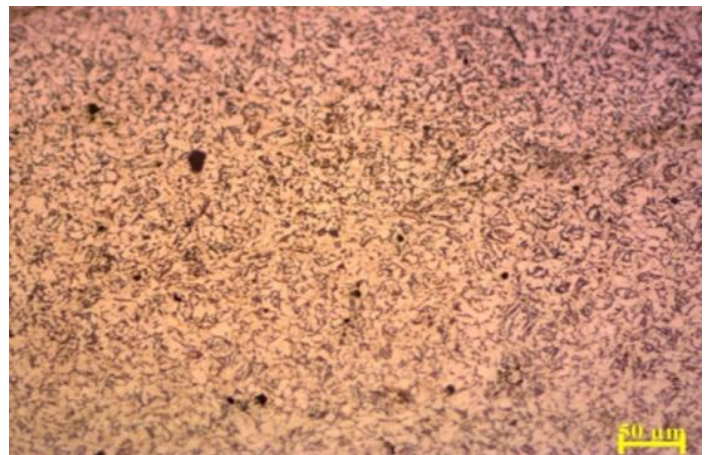

(a)

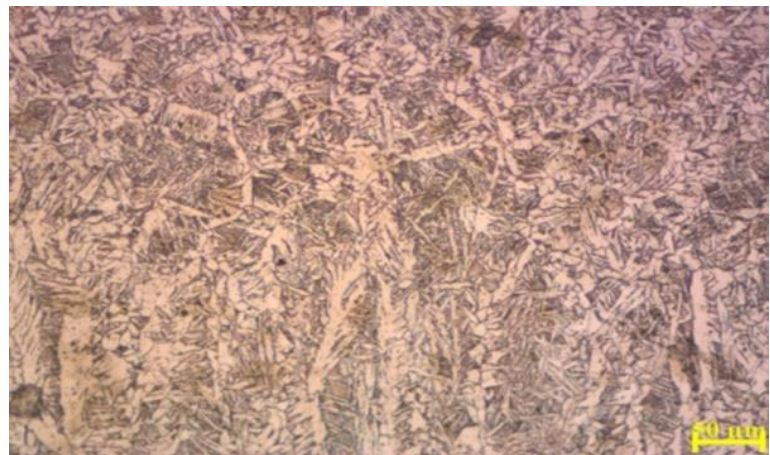

(b)

Figure 3. Microstructure in $1^{\text {st }}$ pass welding region (a) sample 1 (b) sample 2

As in sample 1 the welding operation was done with reverse polarity less heat was generated on the workpiece. Therefore fine grains have been seen. But in sample 2 the welding was carried out with straight polarity. Due to that reason more heat occurred in the workpiece and due to recrystallization of grains dendritic columnar structures are formed. After chipping operation the welding operations were done with straight polarity in second pass welding in both the specimens. The detail structures have been given in Figure 4.

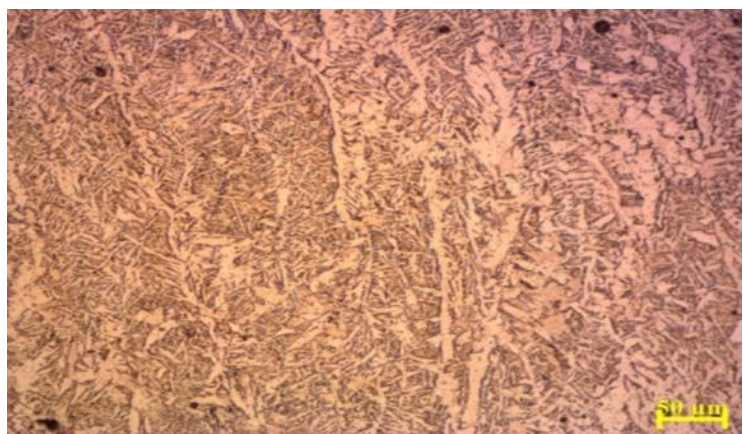

(a)

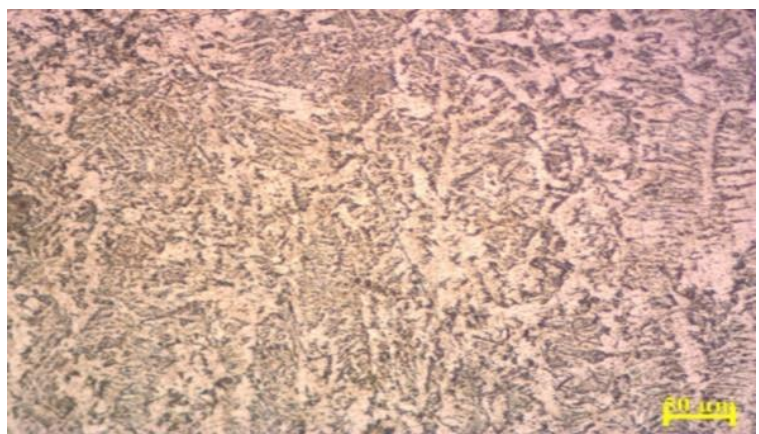

(b)

Figure 4. Microstructure in $2^{\text {nd }}$ pass welding region (a) sample 1 (b) sample 2

Due to high heat input on the workpiece recrystallization of grains occur in both the cases and dendritic columnar structures were seen.In heat affected zone mainly three zones occur i e. metal coarsening zone, transition zone and grain refinement zone. The microstructure of metal coarsening zone for both the welded samples is shown in Figure 5. 


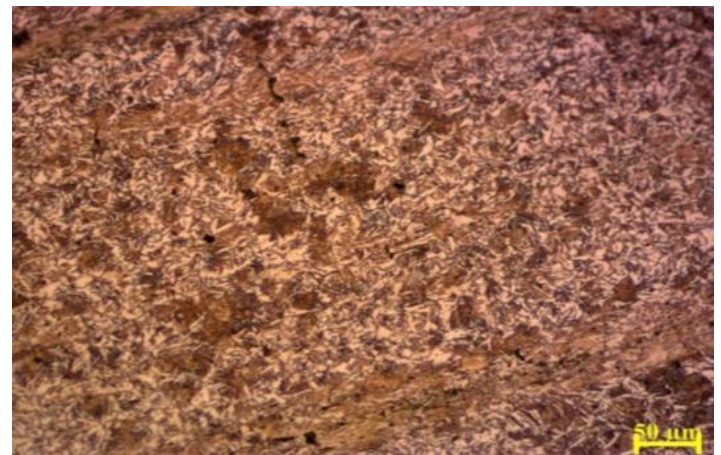

(a)

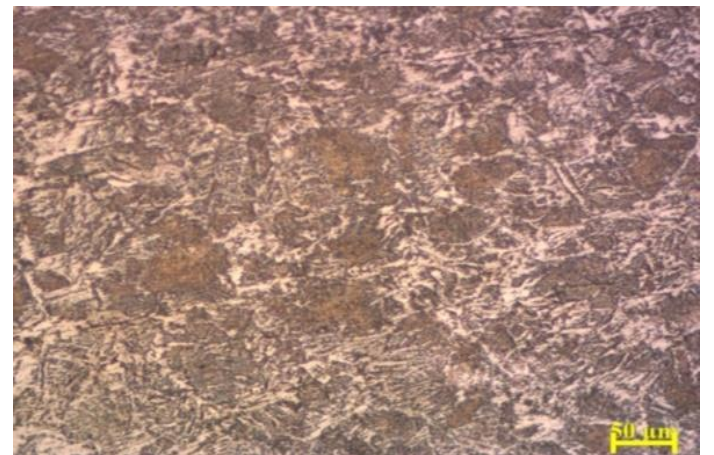

(b)

Figure 5. Grain coarsening zone (a) samle 1 (b) sample 2

Due more amount of heat passing through metal coarsening zone gowth of grains have been occurred. Therefore the grain size is more in the coarsining zone than other zones of heat affected area. In Figure 5(a) one pass is in reverse polarity and in Figure 5(b) both the passes are welded in straight polarity that's why more amount of heat was generated in the second sample. Therefore more growth of grain occurred. The amount of coarse grains has been formed were more in Figure 5(b) as compared to Figure 5(a). When heat passed from coarsening grain towards metal transition zone and away from fusion zone the amount of heat was gradually decreasing. Hterefore the coarseness of grains have been decreased and fine frains were formed which is given in Figure 6.

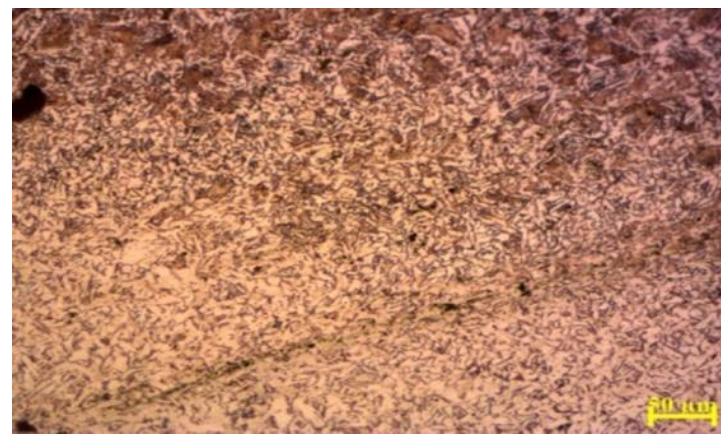

(a)

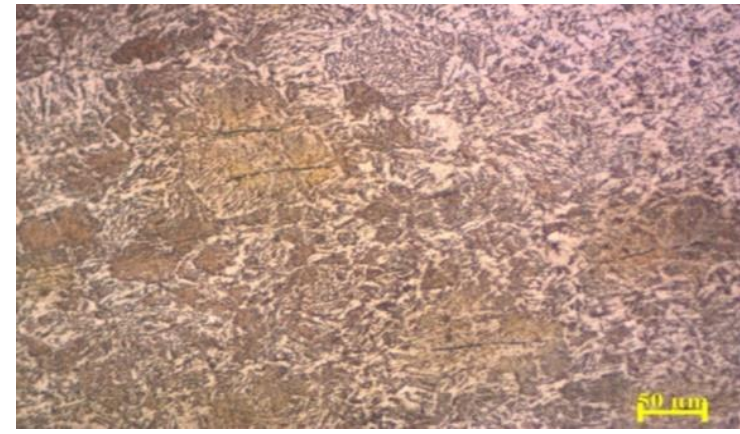

(b)

Figure 6. Metal transition zone (a) sample 1 (b) sample 2

Figure 6(a) explains how coarse grain transform into small fine grains. In the same way in Figure 6(b) the large corse graings convert into fine grains. The amout of heat decreased from trainsition zone to grain refinement zone. Therefore small fine grains have been fomed and the details are given in Figure 7. 


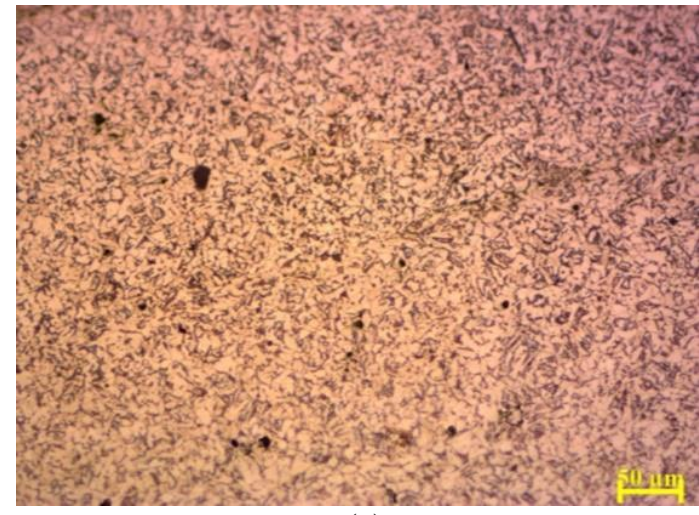

(a)

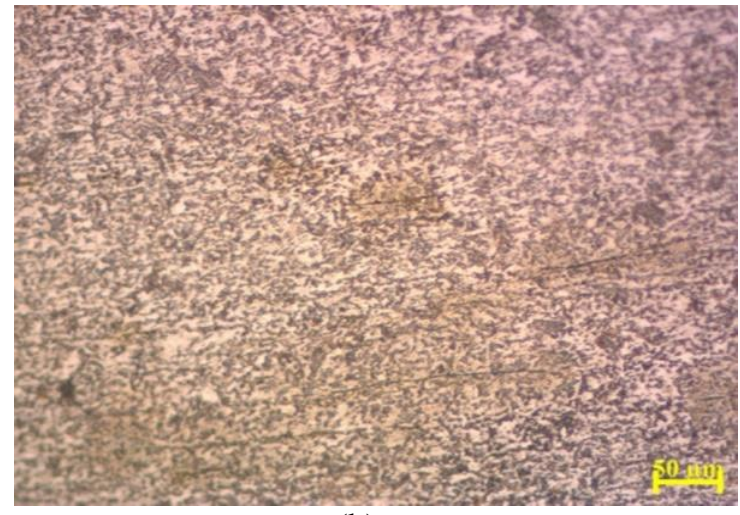

(b)

Figure 7. Grain refinement zone (a) sample 1 (b) sample 2

Due to the low amount of heat less amount of gowthof grains was occurred in grain refinement zone. Therefore fine grains have been seen. But as more amount of heat have been passes through sample 2 than sample 1 that's why the grains sizes in Figure 7(a) are less as compare to Figure 7(b).

\subsection{Impact Strength}

The impact energy of the welded samples increases with increase in the thickness of the material. At the same time, the impact energy decreases with an increase in the value of welding current. The investigation of the effect of welding current on impact energy of SMAW has been done (Talabi et al., 2014). They found a similar trend of decrease in the value of impact energy with an increase in the value of the current. The comparison between the impact toughness of two different processes of welding in SMAW has been given in Table 3.

Table 3. Comparison of impact toughness values for both the welding processes

\begin{tabular}{cccc}
\hline Material thickness $(\mathrm{mm})$ & Current $(\mathrm{A})$ & $\begin{array}{c}\text { Impact toughness values of } \\
\text { one reverse and one straight } \\
\text { polarity welding }\left(\mathrm{J} / \mathrm{m}^{2}\right)\end{array}$ & $\begin{array}{c}\text { Impact toughness values of } \\
\text { both passes with straight } \\
\text { polarity welding }\left(\mathrm{J} / \mathrm{m}^{2}\right)\end{array}$ \\
\hline 5 & 120 & 15.923 & 17.187 \\
\hline 6 & 120 & 12.47 & 13.281 \\
\hline 8 & 120 & 10.987 & 11.232 \\
\hline 5 & 140 & 14.248 & 15.349 \\
\hline 6 & 140 & 11.87 & 12.741 \\
\hline 5 & 140 & 9.574 & 10.277 \\
\hline 6 & 160 & 12.814 & 13.877 \\
\hline 8 & 160 & 9.280 & 10.964 \\
\hline
\end{tabular}

The graph between impact toughness vs current is presented in Figure 8 . 
International Journal of Mathematical, Engineering and Management Sciences

Vol. 4, No. 2, 521-530, 2019

https://dx.doi.org/10.33889/IJMEMS.2019.4.2-042

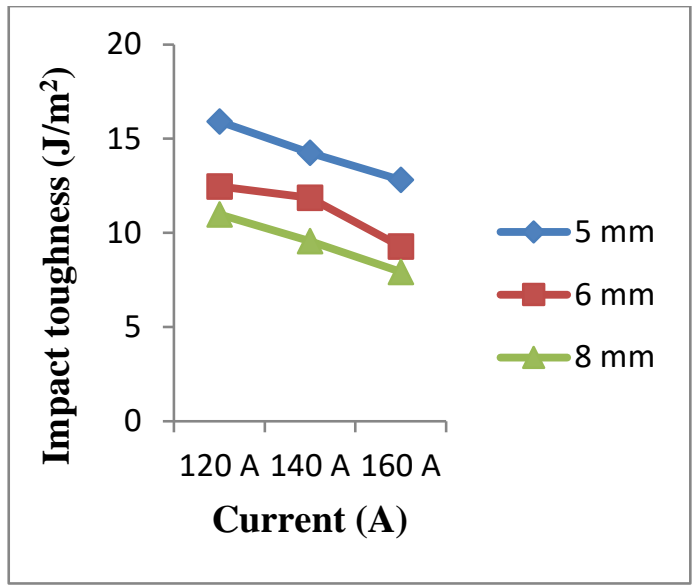

(a)

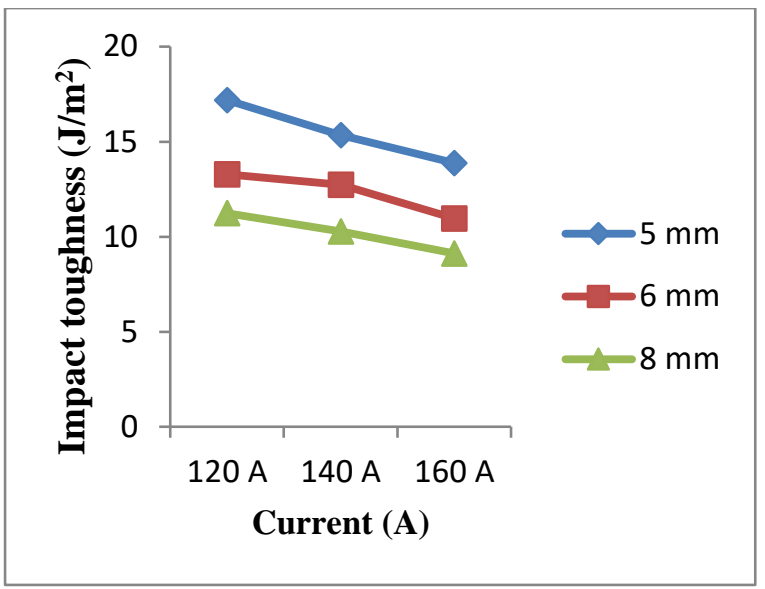

(b)

Figure 8. Comparison of graph between impact strength and current for (a) process 1 (b) process 2

In Figure 8(a) the impact toughness vs current of welded samples with one pass was in reverse polarity and another was in straight polarity has been described. With the increase in current value the impact toughness is decreasing and by increasing the material thickness the impact toughness increases. The reason in that with increase in material thickness more energy absorption has occurred that's why impact toughness increases. In Figure 8(b) the impact toughness vs current has been presented for both the passes of welding were in straight polarity. Here also the figure follows the same trend like Figure 8(a) but due to both the passes of welding were in straight polarity therefore more heat was dissipated on workpiece than $1^{\text {st }}$ process. Therefore, the impact energy of the welded specimens is more as compared to the $1^{\text {st }}$ process.

\section{Conclusions}

Mild steel samples of three different thicknesses were welded using SMAW welding technique with input current of 120A, 140A and 160A respectively. From the microstructural analysis, it was observed that the fusion zone consisted of columnar structure of $\alpha$-ferrite in straight polarity welding and due to low heat input in reverse polarity welding the grains are relatively fine in 1st process of welding. But in the $2^{\text {nd }}$ process microstructure of both the passes are columnar in nature. HAZ zone consisted of $\alpha$-ferrite and colonies of pearlite of various grain sizes. Large grains of ferrite and coarse colonies of pearlite were found in the Grain Coarsening Zone in both the processes. But in the second process due to large heat input larger grains are seen than $1^{\text {st }}$ process. There was a rapid decrease in the grain size in the Grain Refinement zone. Both in the metal transition zone and grain refinement zone the grains are large in size in $2^{\text {nd }}$ process of welding than $1^{\text {st }}$ process.

Impact toughness has been calculated for both the processes. Due to the increase in current impact toughness decreases. The impact toughness value increases with increase in material thickness. This type of trend has been seen in both the processes. But due to more heat input in the $2^{\text {nd }}$ process more energy absorption has been occurred that's why the impact toughness values are more in the $2^{\text {nd }}$ process as compare to $1^{\text {st }}$ process. As more heat input was transferred to work piece in double pass straight polarity welding, therefore the impact toughness was more and better as compared to double pass welding where the $1^{\text {st }}$ pass was in reverse polarity and $2^{\text {nd }}$ was straight polarity. 
International Journal of Mathematical, Engineering and Management Sciences

Vol. 4, No. 2, 521-530, 2019

https://dx.doi.org/10.33889/IJMEMS.2019.4.2-042

\section{Conflict of Interest}

The authors confirm that there is no conflict of interest to publish the paper in the journal.

\section{Acknowledgment}

This research article is not possible without the support of the Department of Industrial Design and laboratory of the Department of Metallurgical and Materials Engineering. I would also like to thank the institute NIT Rourkela, Odisha, India-769008 which supported us to carry out the research work.

\section{References}

Aronov, I., \& Zazhigalkin, A. (2017). Diffusion of innovations: patenting or standardization. International Journal of Mathematical, Engineering and Management Sciences, 2(2), 64-73.

Bodude, M. A., \& Momohjimoh, I. (2015). Studies on effects of welding parameters on the mechanical properties of welded low-carbon steel. Journal of Minerals and Materials Characterization and Engineering, 3(3), 142.

Chennaiah, M. B., Kumar, P. N., \& Rao, K. P. (2016). Influence of heat input and PWHT on the microstructure and mechanical properties in dissimilar (IS2062-EN8) welded joints. Procedia Computer Science, 85, 54-61.

Du Wansheng, P. Y., Lin, Z., \& Zhiling, T. (2008). Microstructure and mechanical properties of MIG welded joint of high nitrogen austenite stainless steel [J]. Welding \& Joining, 12, 009.

Gera, A. E. (2018). A comparison of start-up demonstration test procedures based on a combinatorial approach. International Journal of Mathematical, Engineering and Management Sciences, 3(3), 195219.

Gunwant, D. (2019). Stress concentration studies in flat plates with rectangular cut-outs using finite element method. International Journal of Mathematical, Engineering and Management Sciences, 4(1), 66-76.

Gunwant, D., Anjali, Malik, R., Bhandari, S., Pant, A., Saxena, A., Seema, Kumar, N., Chotrani, N., \& Sah, P. L. (2017). Fabrication and mechanical testing of egg shell particles reinforced Al-Si composites. International Journal of Mathematical, Engineering and Management Sciences, 2(1), 53-62.

Hooda, A., Dhingra, A., \& Sharma, S. (2012). Optimization of mig welding process parameters to predict maximum yield strength in AISI 1040. International journal of Mechanical Engineering and Robotics Research, 1(3), 203-213.

Jagtap, K. R., Rojekar, M. S., Dravid, S. V., \& Deshpande, A. R. (2017). Effect of welding parameters on tensile \& yield strength of is 2062 grade steel using design of experiment approach. Materials Today: Proceedings, 4(8), 7875-7883.

Lala, S. D., Biswas, A., Debbarma, J., \& Deoghare, A. B. (2018). Study of hardness of the weld bead formed by partial hybrid welding by metal inert gas welding and submerged arc welding at three different heat inputs. Materials Today: Proceedings, 5(5), 13650-13657.

Muhammad, A., \& Rushdi, A. (2018). Utilization of Karnaugh maps in multi-value qualitative comparative analysis. International Journal of Mathematical, Engineering and Management Sciences, 3(1), $28-46$.

Saito, Y., \& Dohi, T. (2018). Parametric bootstrap methods for estimating model parameters of nonhomogeneous Gamma process. International Journal of Mathematical, Engineering and Management Sciences, 3(2), 167-176.

Srivastava, S., \& Garg, R. K. (2017). Process parameter optimization of gas metal arc welding on IS: 2062 mild steel using response surface methodology. Journal of Manufacturing Processes, 25, 296-305. 
International Journal of Mathematical, Engineering and Management Sciences

Vol. 4, No. 2, 521-530, 2019

https://dx.doi.org/10.33889/IJMEMS.2019.4.2-042

Talabi, S., Owolabi, O. B., Adebisi, J. A., \& Yahaya, T. (2014). Effect of welding variables on mechanical properties of low carbon steel welded joint. Advances in Production Engineering \& Management, 9(4), 181-186.

Wang, L., \& Alexander, C. A. (2016). Additive manufacturing and big data. International Journal of Mathematical, Engineering and Management Sciences, 1(3), 107-121. 